\title{
Bases teóricas para a compreensão do trabalho de campo como metodologia de ensino da Geografia e Educação Ambiental
}

Theoretical bases for understanding fieldwork as a methodology for teaching Geography and Environmental Education

Bases teóricas para entender el trabajo de campo como metodología para la enseñanza de Geografía y Educación Ambiental

Rita Denize de Oliveira Professora Doutora, UFPA, Brasil ritadenize@ufpa.br

José Augusto Lopes da Silva Professor, Mestrando Universidade do Estado do Pará, Especialista em Educação, Universidade Norte do Paraná (Unopar), SEDUC-Pa, Brasil. augustolopes10@yahoo.com.br

Amanda Cristina Oliveira Gonçalves Professora Mestre, Fundação Centro de Referência em Educação Ambiental Escola Bosque "Professor Eidorfe Moreira", Brasil. ccb.amanda@gmail.com 


\begin{abstract}
RESUMO
A geografia escolar tem como principal característica a síntese, constitui-se num escopo teórico com conteúdo variando da astronomia, geologia, agronomia, meteorologia, agregando seus próprios conceitos e categorias de análise: espaço geográfico: paisagem, território e lugar. Entretanto, esse exercício no contexto da sala de aula, ao longo dos anos, transformou a disciplina em excessivamente teórica, e pouco acessível aos estudantes, entretanto, criou técnicas específicas de reprodução dos conhecimentos fundamentadas na repetição e memorização. Neste sentido, esse artigo propõe tratar de bases teóricas que apontam a relevância dos trabalhos de campo na consolidação do processo de ensino - aprendizagem, adentrando a educação básica e o ensino superior no âmbito do Programa Residência Pedagógica de Geografia. A pesquisa foi desenvolvida por meio de experiências práticas realizadas na Ilha do Combú com graduandos do curso de Geografia da Universidade Federal do Pará, na Ilha de Caratateua com alunos do ensino fundamental e do ensino médio da Escola Bosque. Das teorias que fundamentam a investigação, funcionando como suporte a análise dos dados obtidos, destacam-se a Teoria da Complexidade de Edgar Morin e a Teoria da Aprendizagem Significativa de David Ausubel, ambas relacionadas às novas perspectivas metodológicas de ensino aprendizagem da geografia. As experiências práticas proporcionadas pelo trabalho de campo se revelam com grande potencial para a reversão do ensino tradicional e mecanicista que ainda persiste na área, estabelecendo uma compreensão mais complexa dos diversos sistemas estabelecidos pelos sujeitos locais, bem como um maior entendimento da relação homem $x$ ambiente nos estudos da geografia ambiental.
\end{abstract}

PALAVRAS-CHAVE: Educação Ambiental. Ensino. Geografia Escolar.

\begin{abstract}
School geography has synthesis as its main characteristics, constituting a theoretical scope with content ranging from astronomy, geology, agronomy, meteorology, adding its own concepts and categories of analysis: geographical space: landscape, territory and place. However, this exercise in the classroom context, over the years, transformed the discipline into excessively theoretical, and little accessible to students, however, it created specific techniques for the reproduction of knowledge based on repetition and memorization. In this sense, this article proposes to deal with theoretical bases that point out the relevance of fieldwork in the consolidation of the teaching - learning process, entering basic education and higher education within the scope of the Pedagogical Residency Program in Geography. The research was developed through practical experiences carried out in Ilha do Cumbu with undergraduate students of the Geography course at the Federal University of Pará, in Ilha de Caratateua with students from elementary and high school at Escola Bosque. Of the theories that underlie the investigation, functioning as a support for the analysis of the data obtained, we highlight the Complexity Theory of Edgar Morin and the Theory of Meaningful Learning by David Ausubel, both related to the new methodological perspectives of teaching geography learning. The practical experiences provided by the fieldwork reveal great potential for the reversion of traditional and mechanistic education that still persists in the area, establishing a more complex understanding of the various systems established by local subjects, as well as a greater understanding of the relationship between man and environment in the study of elements of environmental geography.
\end{abstract}

KEY WORDS: Environmental education. Teaching. School Geography.

\title{
RESUMEN
}

La geografía escolar tiene la síntesis como sus características principales, constituyendo un alcance teórico con contenido que abarca desde astronomía, geología, agronomía, meteorología, agregando sus propios conceptos y categorías de análisis: espacio geográfico: paisaje, territorio y lugar. Sin embargo, este ejercicio en el contexto del aula, a lo largo de los años, transformó la disciplina en excesivamente teórica y poco accesible para los estudiantes, sin embargo, creó técnicas específicas para la reproducción del conocimiento basadas en la repetición y la memorización. En este sentido, este artículo propone abordar las bases teóricas que señalan la relevancia del trabajo de campo en la consolidación del proceso de enseñanza - aprendizaje, ingresando a la educación básica y superior en el ámbito del Programa de Residencia Pedagógica en Geografía. La investigación se desarrolló a través de experiencias prácticas llevadas a cabo en Ilha do Cumbu con estudiantes universitarios del curso de Geografía en la Universidad Federal de Pará, en Ilha de Caratateua con estudiantes de primaria y secundaria en Escola Bosque. De las teorías que subyacen a la investigación, que funcionan como soporte para el análisis de los datos obtenidos, destacamos la teoría de la complejidad de Edgar Morin y la teoría del aprendizaje significativo de David Ausubel, ambas relacionadas con las nuevas perspectivas metodológicas de la enseñanza del aprendizaje de la geografía. Las experiencias prácticas proporcionadas por el trabajo de campo revelan un gran potencial para la reversión de la educación tradicional y mecanicista que aún persiste en el área, estableciendo una comprensión más compleja de los diversos sistemas establecidos por los sujetos locales, así como una mayor comprensión de la relación entre el hombre y el medio ambiente. en el estudio de elementos de geografía ambiental.

PALABRAS CLAVE: Educación ambiental. enseñanza Geografía escolar. 


\section{INTRODUÇÃO}

A geografia que é ensinada em contexto escolar ainda apresenta metodologias de ensino marcadamente tradicionais, com características que não conseguem contribuir significativamente para a formação social, científica e política do aluno, uma vez que essa geografia é representada principalmente pela enumeração dos dados geográficos, com a apresentação dos espaços de forma fragmentada, onde se opera com questões desconexas, isolando-as ao invés de tratar o espaço como complexo. Esse espaço não é compreendido, na maioria das vezes, como aquele que se apresenta ao aluno em sua vivência diária, fazendo-o partir para estratégias de sobrevivência em meio a esse modelo de educação, como estabelecer árdua memorização dos conteúdos, por exemplo.

O caráter científico da geografia, que leva a um ensino pautado na síntese ou priorização de conteúdos relacionados aos dados geográficos em detrimento dos demais, reflete uma herança de construção do positivismo. Entretanto, ao se perceber essas características, torna-se necessário superar tal realidade a partir de uma nova forma de "ensinar o mundo", uma vez que este é dinâmico e suas mudanças operam aceleradamente e mutuamente, principalmente no contexto da educação geográfica ambiental.

Segundo Morin (2007), a reforma necessária para a obtenção de uma nova forma de pensar o mundo, requer o conhecimento do contexto e do complexo que confronte a causalidade linear. Do contexto, uma vez que busca uma inseparabilidade e as inter-retro-ações entre o fenômeno e seu contexto e, deste com o contexto planetário. Complexo, por ser um pensamento que capte relações e inter-relações, implicações mútuas e fenômenos multidimensionais, que respeite diversidade e ao mesmo tempo a unidade, um pensamento organizador que conceba a relação reciproca entre todas as partes.

A busca por metodologias no ensino da geografia que possam proporcionar essa integralidade do saber junto a novas práticas educacionais, devem atentar para uma aprendizagem que, segundo Ausubel (1973), seja capaz de levar em consideração a estrutura cognitiva do aluno e seu conhecimento prévio, proporcionando uma interação de forma significativa que provoquem mudanças nessas estruturas, levando a uma aprendizagem que denomina de Aprendizagem Significativa.

Nesse sentido, esse artigo tem como premissa fundamental propor uma discussão teórica sobre a importância do trabalho de campo para o ensino da geografia e suas contribuições para a estruturação de uma educação ambiental eficaz, dialogando com a Teoria da Complexidade de Edgar Morin (2007), que proporciona uma visão de mundo indissociável junto a uma abordagem multidisciplinar e multirreferenciada, buscando também aproximação com a Teoria da Aprendizagem Significativa de David Ausubel, no sentido da construção de novas ideias a partir de estruturas cognitivas já existentes e que devem ser levadas em consideração no processo de aprendizagem em geografia. Para tanto foram associadas experiências práticas desenvolvidas na Fundação Centro de Referência em Educação Ambiental Escola Bosque "Professor Eidorfe Moreira", localizada na Ilha de Caratateua em Belém, Pará, referência na América Latina no ensino de educação ambiental. 


\section{OBJETIVOS}

Proporcionar uma discussão teórica sobre a importância do trabalho de campo no contexto de ensino aprendizagem da geografia, bem como sua contribuição para a estruturação de uma educação ambiental crítica.

Desenvolver a compreensão dos conceitos fundamentais da geografia a partir do contato com a vivência na região das ilhas e do trabalho direto com a realidade dos sujeitos que ocupam esses espaços.

Caracterizar o processo ensino aprendizagem em geografia e educação ambiental na Fundação Centro de Referência em Educação Ambiental Escola Bosque "Professor Eidorfe Moreira", localizada na Ilha de Caratateua em Belém, Pará.

\section{METODOLOGIA / MÉTODO DE ANÁLISE}

\section{Localização da área de estudo}

A Ilha de Caratateua em Outeiro, está localizada na Região Metropolitana de Belém, Nordeste do Estado, em áreas de ilhas que pertencem ao distrito administrativo de Belém, a Fundação Centro de Referência em Educação Ambiental Escola Bosque "Professor Eidorfe Moreira", localizada na Av. Nossa Sra. da Conceição - São João do Outeiro (Outeiro), Belém - PA, 66840450.

Figura 01: Localização da área de Estudo

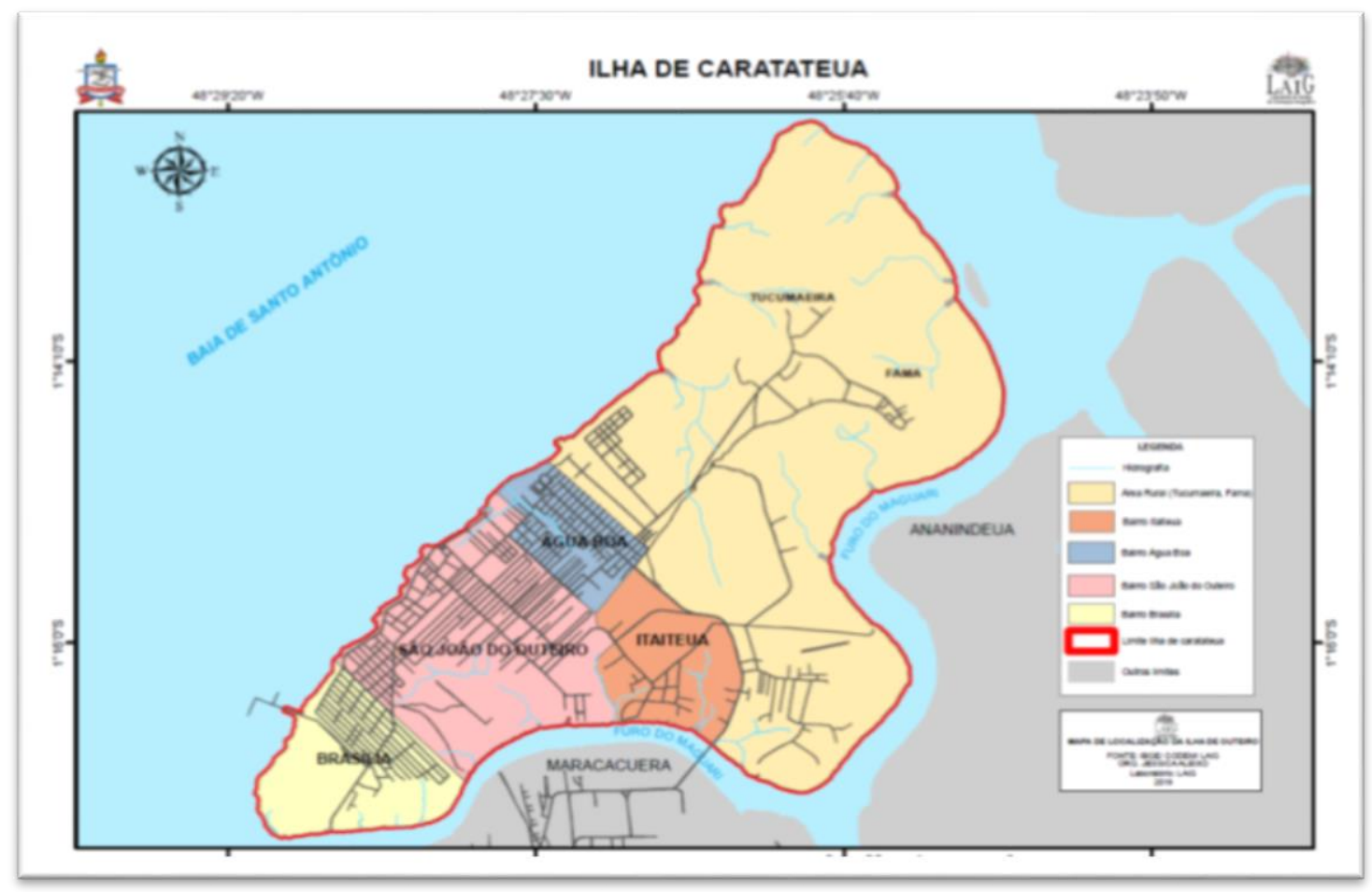

Fonte: ALEIXO. 2019. 


\section{Roteiro metodológico}

Para o desenvolvimento da pesquisa, foi realizado inicialmente o levantamento bibliográfico da área de estudo, para a obtenção de dados históricos sobre a formação da llha de Caratateua em Outeiro- Pará. Tal estudo foi realizado através da pesquisa sistemática em artigos, dissertações e teses, bem como o acesso a decretos estaduais sobre a fundação do distrito de Outeiro.

A evolução do uso atual do solo foi verificada por meio da análise de imagens de satélite Landsat nas bandas 3, 4 e 5, com o auxílio de software ArcGis 10.5 para a identificação das dinâmicas envolvidas no processo de formação e ampliação do Parque. Associado a esta fase da pesquisa de campo, pode-se utilizar os registros fotográficos para a finalização do mapeamento.

Posteriormente, foi realizada uma visita a sítios no bairro do Fama, no dia 04 de junho de 2019, de onde foram coletados relatos e entrevistas conduzidas pelos alunos, bem como o uso de GPS e o registro fotográfico na llha do Combú e llha de Caratateua em Outeiro.

\section{BASES TEÓRICAS}

\section{A aprendizagem significativa e a complexidade como religação de saberes}

A teoria da complexidade surge em virtude do avanço da globalidade durante o século XXI, seus conceitos contrapõem-se aos princípios cartesianos de fragmentação do conhecimento e propõem outra forma de pensar os problemas conjunturais. Assim, a teoria da complexidade se propõe a realizar a religação dos saberes compartimentados em áreas e subáreas. De acordo com Morin (2007) o ensino no terceiro milênio representa um grande desafio:

\footnotetext{
Em parte, porque estamos numa época de saberes compartimentados e isolados uns dos outros, não se trata apenas da especialização, mas da hiperespecialização porque as especializações não chegam a comunicar uma com as outras. Uma justaposição de compartimentos que faz esquecer as comunicações e as solidariedades entre os conhecimentos especializados que constituem o reinado dos experts, isto é, de técnicos especialistas que tratam o problema de modo isolado e esquecem que nessa época de mundialização os grandes problemas são transversais, multidimensionais e planetários (MORIN, 2007, p.32).
}

A crise paradigmática está relacionada à ineficiência do paradigma fragmentário em fornecer possibilidades de soluções a problemas ambientais de ordem planetária como clima, e até mesmo questões políticas e econômicas. Para isso, apresenta cinco princípios da complexidade: a) Princípio holográfico, b) Princípio da transdisciplinaridade, c) Princípio de complementaridade dos opostos, d) Princípio da incerteza e, f) Princípio da autopoiese.

A importância do trabalho de campo para realização de uma metodologia que busque utilizar a teoria da complexidade é imprescindível, pois permite ao aluno compreender vários elementos constituídos ao longo do processo de ensino, trabalhando em conjunto para o entendimento do espaço com maior integralidade. Para a geografia, que é a ciência das relações, permite a visualização de conceitos e categorias como paisagem, região, local e global, além de desenvolver uma percepção ambiental centralizada no convívio do homem com o seu meio 
ambiente.

Morin (2007) demonstra que hoje a capacidade de relacionar os diversos tipos de conhecimento torna-se mais necessária, pois sempre será necessário raciocinar para compreender os mais variados símbolos, por tanto o metafísico torna-se algo puramente humano e jamais máquina alguma poderá assumir este papel, o qual a própria natureza designou ao ser humano, Immanuel Kant em sua obra "Fundamentação da Metafísica dos Costumes" demonstra essa singularidade que o ser humano possui.

Por sua vez a Teoria da Aprendizagem Significativa de David Ausubel compreende que o processo de aprendizagem deve ser relacionado com a produção de um conhecimento ligado ao aluno através de relações que tenham significado, ou seja, que façam sentido a partir das estruturas cognitivas já presentes (PDIZZARI et al, 2002). Dessa forma, esta teoria, aliada ao trabalho de campo, pode contribuir para que o estudante compreenda com mais eficácia o conceito de lugar, partindo para reflexões profundas sobre seu eu no mundo e as relações que implicam disso, Santos (2000) destaca que esse processo vai de encontro à fase mais complexa da globalização, onde as partes estão no todo assim como o todo está nas partes, como indicado por Morim (2007).

Entender o seu lugar no mundo e compreender como a realidade funciona, permite ao aluno ter uma noção de classe, podendo assim localizar-se cartograficamente nos mais diversos espaços. O conteúdo geográfico ganha vida e o estudante, através de seus conhecimentos prévios, pode construir ideias, ao contrário do método tradicional que prioriza a aprendizagem mecânica. Ausubel (1973) enfatiza que aprendizagem mecânica é caracterizada por não encontrar informações prévias na estrutura cognitiva dos alunos com a qual estabeleça relação, e por isso acaba não promovendo integração e armazenamentos de novas informações.

Nesse contexto, a Teoria da Aprendizagem Significativa aliada à Teoria da Complexidade permite pensar o aluno não apenas como um objeto que precisa ser preenchido de conteúdo e sim como ser humano pensante, capaz de encontrar resposta e se autoconstruir. De forma geral, o tipo de aprendizagem que se produz no meio escolar é por descoberta, os conteúdos geográficos são recebidos de modo não completamente acabados e o aluno deve defini-los ou "descobri-los" antes de assimila-los, porém, ao longo do processo isso acaba sendo reduzido a uma aprendizagem mecânica e repetitiva. A aprendizagem receptiva é a mais eficaz, pois os conteúdos a serem aprendidos são dados ao aluno em sua forma final, já acabada, relaciona o novo conteúdo de maneira substancial com algum aspecto da estrutura cognitiva prévia que lhe for relevante. (PELIZZARI et al, 2002; p. 39)

O conhecimento geográfico difundido na escola, por vezes torna-se muito distante da realidade do aluno, pouco aproveitável nas suas necessidades cotidianas. Na sua Teoria, Ausubel apresenta uma aprendizagem que tenha como ambiente uma comunicação eficaz, que conduza o aluno a imaginar-se como parte integrante desse novo conhecimento através de elos, de termos familiares a ele. Através da palavra, o educador pode diminuir a distância entre a teoria e a prática na escola, capacitando-se de uma linguagem que ao mesmo tempo desafie e leve o aluno a refletir. (PELIZZARI et al, 2002; p. 41p) 


\section{Pesquisa de campo integrando educação básica e ensino superior - residência pedagógica}

No ensino em geografia, onde o aluno de graduação precisa colocar em prática o seu conhecimento e ao mesmo tempo ajusta-lo com o modo de vida do aluno na educação básica, observa-se a necessidade constante da troca de saberes e da ênfase na relação entre a educação básica e o ensino superior, de forma que se tenha intensificada a relação teoria e vivido, pratica e aprendizado.

O trabalho de campo que envolva a educação básica e o ensino superior na troca de saberes é essencial para a universidade, por cumprir seu papel básico social. Nesse caso, pode inserir também a participação da população e da comunidade não acadêmica em diferentes escalas, nas estratégias de ensino aprendizagem desenvolvidas. Cavalcanti (1998) expressa que tal integração é fundamental para a relação sujeito-aluno, dentro da base da formação críticosocial, também ampliando o papel do professor como mediador nessa troca de conhecimento.

A partir dessa troca de conhecimento e o fortalecimento do pensamento crítico do aluno, o trabalho de campo ganha aspectos intrínsecos em relação ao método de ensino-aprendizagem, pois se insere a vivência do aluno nas discursões de sala de aula. Além disso, ao aproximar o aluno da educação básica ao contexto universitário, é possível instiga-lo a ampliar interesses inerentes aos desenvolvidos no meio científico, de forma que futuramente o mesmo possa contribuir com conhecimentos advindos seu lugar, suas vivências e origens.

Castrogiovani et al. (2016 p. 16) ressalta a capacidade da geografia em instigar e fazer com que os alunos possam atuar de maneira mais ativa na sociedade, ampliando seu lugar político que é inerente ao meio social. Neste sentido, o trabalho de campo é capaz de reafirma essas práticas críticas voltadas para o seu meio onde está inserido. Libâneo (1995), em seus estudos, defende o viés interacionista entre professor, aluno e o meio de vivência de ambos, baseado na troca de sentidos que engloba também a intersubjetividade, sem deixar o viés critico no modo de ensinar e aprender.

O professor de geografia tem grande importância nessa relação de ensino aprendizagem, uma vez que seu papel de mediação abrange as ideias de hierarquias que influenciam diretamente no comportamento do aluno e de seu desempenho, uma vez que se baseia no modo de interação do professor materializado por meio da didática. Esta por sua vez, quando é desenvolvida de forma abrangente evidencia o modo de pensar do aluno e do professor, a geografia da memorização, que já sofreu inúmeras críticas, ainda está presente na relação aluno x professor das escolas básicas, problema também existente na maneira de ensinar do professor no ensino superior.

Nesse caso a dinâmica entre o ensino superior e a educação básica deve ser moldada nos dois extremos, desde o professor do ensino superior, através de metodologias que possam instigar o aluno de graduação a desenvolver práticas metodológicas de ensinar, a escola básica, através de políticas de dinamização estratégicas entre o ensino básico e o superior. Assim, o trabalho de campo surge como uma das metodologias aplicadas para o fortalecimento dessas práticas metodológicas, visando fortalecer a relação ente o aluno e o professor e preparando o senso crítico deste para que melhor compreenda o lugar de vivência. 


\section{RESULTADOS}

A cidade de Belém- Pará possui um ambiente insular constituído por 39 ilhas de elevada geodiversidade dentre as quais está à Ilha do Combú, onde foi realizada a primeira experiência, coordenada pelas professoras orientadoras do Programa Residência Pedagógica- PRP e os discentes bolsistas e voluntários do curso de geografia inseridos no programa.

Um dos objetivos do trabalho de campo era proporcionar aos discentes um maior contato com a vivência da região das ilhas, uma vez que grande parte dos alunos que estudam atualmente na Escola Bosque Professor Eidorfe Moreira e a Escola de Ensino Fundamental Monsenhor Azevedo é originária das regiões das ilhas. Mesmo se tratando da Escola Monsenhor de Azevedo, que se localiza na área urbana de Belém, Igreja de São Judas, Bairro da Condor, recebe inúmeros estudantes advindos das ilhas e são transportados diariamente por via fluvial, sendo essencial o desenvolvimento de uma educação ambiental diretamente com os alunos e moradores.

A Ilha do Combú é a maior ilha localizada na porção Sul do município de Belém, desde 1997, configura-se em uma área de Unidade de Conservação caracterizada como APA, Área de Proteção Ambiental pela Lei 6.083 de 13 de novembro de 1997 (PARA, 1997), com a finalidade de conter a derrubada de palmeira de açaí para extração de palmito.

Por longos anos imaginava-se a ineficiência da produção dos solos de várzeas, pode-se observar nestas áreas certa fertilidade e diversidade de cobertura vegetal. Entre as principais atividades da ilha do Combú estão o extrativismo do fruto do açaí, em suas duas comunidades Periquitaquara e Combú.

As florestas de várzea são ambientes periodicamente inundados, influenciados pelos regimes de marés, apresentando períodos de enchentes e vazantes, que provocam variação constante no ambiente. São ambientes frágeis, com origem e funcionamento ligados à deposição de sedimentos geologicamente recentes (QUEIROZ et al. 2007; MOURA, ILKIU-BORGES e BRITO, 2013).

Além de atividades vinculadas ao turismo podem-se verificar novos formatos de produção, como o uso sustentável da várzea para a produção de chocolate orgânico na ilha do Combú. A microempresária Izete Costa, conhecida popularmente como Dona Nena, cultiva cacau orgânico nas várzeas. De acordo com relato da mesma o chocolate produzido no Combú é livre de agrotóxicos, os cacaueiros têm um diferencial, pois ao crescem na várzea alta têm amêndoas menores, revestido de maior conteúdo de polpa.

A várzea está subdividida em dois ambientes, várzea alta e várzea baixa, condicionada pelas influencias sedimentares e topográficas que exercem diferenças na estrutura da vegetação. A várzea baixa é constituída por palmeiras, possui menor diversidade em espécies arbóreas florestais e o solo permanece temporariamente alagado, e, é influenciada pelas marés diárias. Na várzea alta são encontradas espécies arbóreas com maior frequência, além de palmeiras, e o solo possui pouca influência hídrica, inundada na ocasião dos equinócios associados a marés de sizígia (ANDERSON \& IORIS 1989, JARDIM \& VIEIRA 2001; SILVA, 2010).

A mão de obra envolvida na atividade é essencialmente familiar, sendo a produção de caráter 
artesanal, que agrega trabalhadores temporários pertencentes à comunidade que ajudam em todo o processamento do cacau: colheita, fermentação, secagem, moagem até se transformarem em produtos diversos como brigadeiro de pote, brigadeiro enrolado, bombons, barra de chocolate refinada, geleia de cacau, licor de cacau e a famosa barrinha rústica. Recentemente, em parceria com a Gaudens Chocolates, de Belém- Pará passou-se a produzir barrinhas refinadas com adição de leite.

Mais do que conhecer o processo de produção de cacau orgânico, o importante foi reforçar com estudantes a relevância dos ambientes de várzea na Amazônia, uma vez que os recursos retirados da várzea permitem a reprodução das comunidades amazônicas. As várzeas são exploradas de diversas formas, principalmente através do extrativismo vegetal como o cultivo do açaí (palmito e fruto), seringa, andiroba e madeira, onde o conhecimento desses modos de produção e ocupação dos espaços produtivos favorece a compreensão do meio onde os alunos estão inseridos, em especial os da Escola Monsenhor de Azevedo e Escola Bosque Professor Eidorfe Moreira e pelos discentes de geografia vinculados ao PRP (Figura 02).

As demais experiências foram realizadas na Ilha de Caratateua, palavra de origem indígena que quer dizer lugar das grandes batatas, regionalmente conhecida como llha do Outeiro. A ilha apresenta amplo histórico de intervenção com forte apelo turístico, pelo número de praias que possui. Atualmente, a possibilidade de conclusão das obras BRT que liga São Brás a Icoaraci por meio de "transporte rápido" transformou a ilha em um espaço vulnerável a movimentos habitacionais planejados como Alfaville e loteamentos clandestinos resultante da intensa especulação imobiliária na ilha. Convivendo com essa realidade encontram-se as áreas que resistiram a essa proposta, são quintais e sítios que continuam sobrevivendo do extrativismo do açaí e outras frutas regionais, da criação de frangos caipiras, produção de mel, pesca, de atividades excessivamente primárias que caracterizam as áreas rurais da Amazônia.

Diante desse contexto um grupo do Programa Residência Pedagógica da Escola Bosque Professor Eidorfe Moreira, em uma turma do ensino fundamental do 7ํ ano, propôs uma aula de campo, no bairro do Fama na Ilha de Caratateua, como ferramenta de ensino de Geografia. Dos Objetivos estavam demonstrar diferenças entre espaço rural e o urbano: paisagem, serviços, atividades econômicas; tendo em vista a valorização de ecossistemas amazônicos como as várzeas (Figura 02). 
Figura 02: Trabalhos de campo realizados nas ilhas do Combú e Caratateua: (a) Discentes do curso de geografia na Ilha do Combú; (b) Trabalho de campo realizado com alunos da Escola Bosque Professor Eidorfe Moreira em áreas de Falésias; (c; d, e) trabalho de campo realizado no bairro Fama com alunos do 70 ano do ensino fundamental evidenciando manejo do açaí; plantio de mudas e presença de hortas suspensas para consumo e venda do excedente.

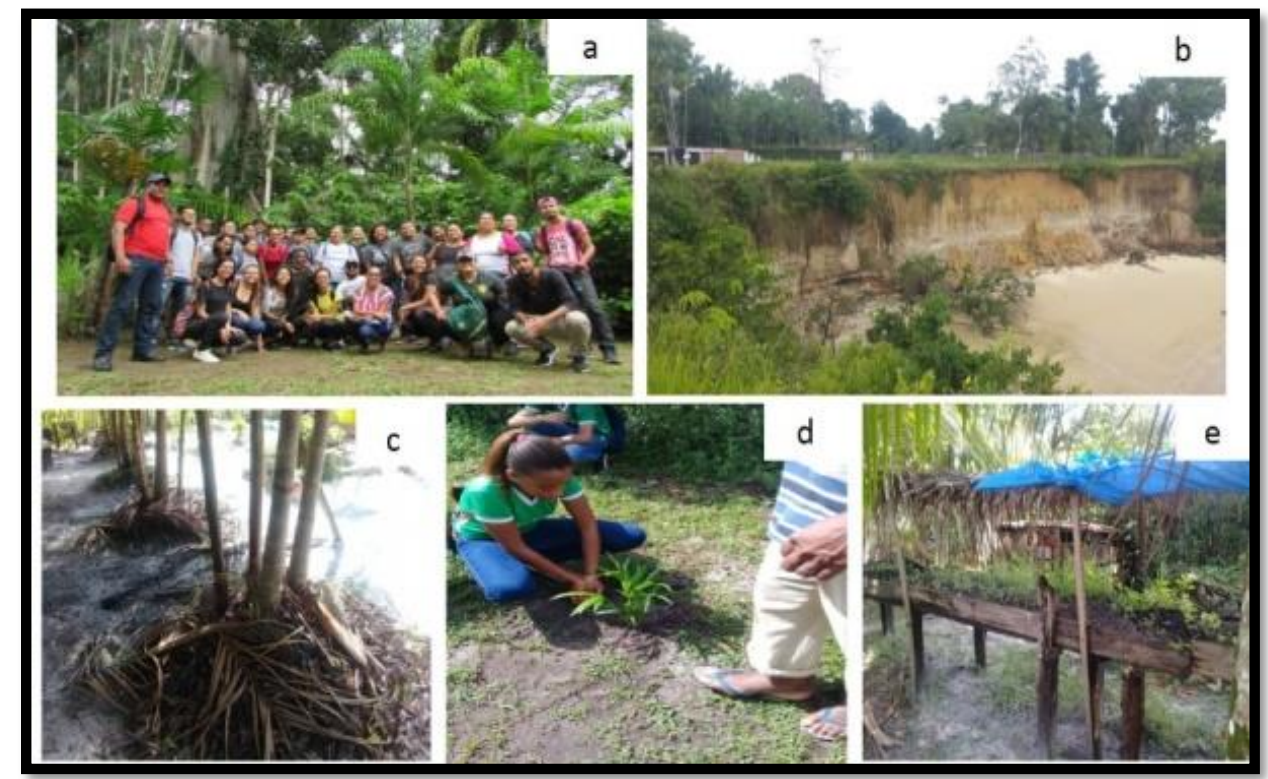

Fonte: (a) LUZ (2018); (b) AIRES (2019); (c, d, e) OLIVEIRA, (2019).

A aula de campo realizada com a participação dos alunos do ensino fundamental proporcionou a visualização dos setores da economia da Ilha, por meio da visita ao Sítio Monte Sião e a observação à circunvizinhança do bairro. 0 sítio apresenta extensão de 40 hectares, do ponto de vista ambiental os alunos identificaram área de patrimônio natural com áreas de paleo, cordões arenosos, indicador de variação do nível marinho pretérito, rica hidrografia pelo contato da propriedade com o furo do Maguari, cuja influência das marés e das precipitações propicia o desenvolvimento de extensas várzeas, áreas de planície fluvial sujeita a inundações periódicas, em função dessa dinâmica hídrica, áreas propicias ao desenvolvimento da palmeira de açaí, que é à base da economia da ilha (Figura 2). 
Figura 03: Mapa Ecossistêmico de Outeiro

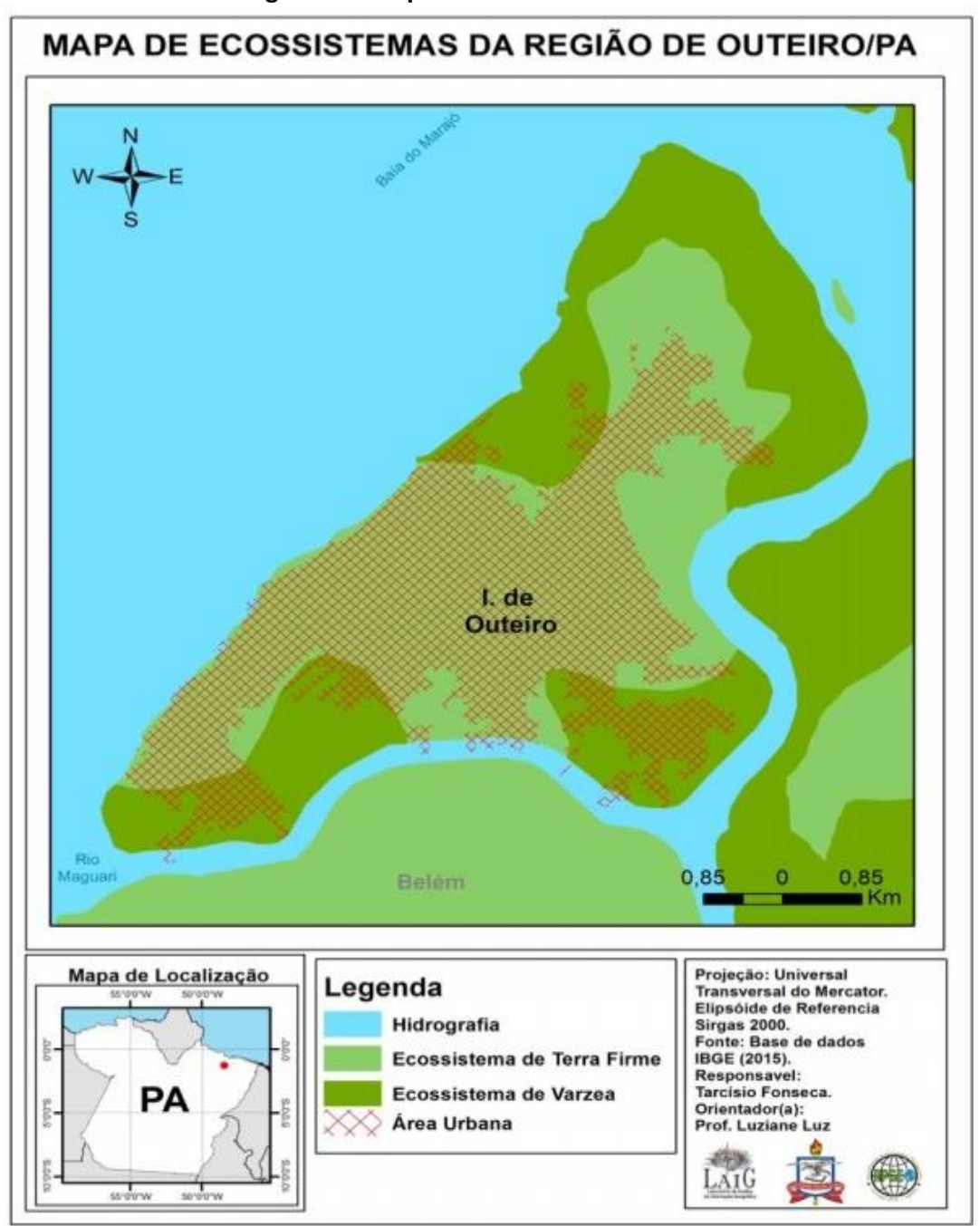

Fonte: FONSECA E LUZ (2019)

As várzeas são manejadas pela mão de obra familiar, migrantes do município de Soure. A produção de açaí in natura e polpa são consumidas na própria ilha de Caratateua, sendo que a coleta é feita tanto na propriedade como porções insulares e funcionando atualmente como principal fonte de renda familiar. Apesar de serem nativos das várzeas, atualmente são manejados por meio com adubo orgânico (caroços do fruto), existe uma orientação da colonização das novas mudas pela família para viabilizarem estrategicamente a colheita, além da retirada das unidades mais antigas, e limpeza dos pés de açaí.

Outro aspecto interessante da comercialização do açaí, constatado por meio do trabalho de campo e das entrevistas realizadas, é que o mesmo integra uma cadeia produtiva descrita desde a etapa de manejo, colheita, transporte e distribuição nos pontos de venda. A sua comercialização in natureza, bem como seu processamento, compõe uma economia popular invisibilizada que sustenta inúmeras famílias na ilha. Em bairros como o Fama e o Itaiteua estão localizados os açaizais, e em bairros como Água Boa o produto é comercializado, compondo um espaço híbrido na ilha do rural e urbano (Figura 01). 
É possível observar que o trabalho de campo é capaz de proporcionar uma maior compreensão das estruturas que constituem os espaços e suas diversas relações. Para Cavalcanti (2012), os três principais objetivos do trabalho de campo em geografia são:

a) Emprego preciso e prático do vocabulário geográfico como: espaço geográfico, paisagem, território e lugar.

Grande parte dos alunos, durante o desenvolvimento da aula de campo demonstraram dificuldades em entender e aplicar termos relacionados aos conceitos geográficos. Neste momento, foi imprescindível um olhar diferenciado por parte dos mediadores, que a todo o momento partiram para tentativas de associação desses termos, "palavras mortas" na concepção do autor, com experiências vivas, que pudessem despertar nos alunos maior compreensão e atribuição de significado.

b) Permite a análise de cartas geográficas; confecção de croquis e outras formas de representação do espaço.

O deslocamento dos alunos pelos espaços proporcionou uma compreensão diferenciada dos conceitos estudados, uma vez que houve possibilidade de se pensar o próprio mapa ou desenho, que antes haviam visualizado apenas no papel. A observação das posições relativas dos objetos no espaço permite desenvolver a noção de orientação de escala cartográfica e mostra sua utilidade em situações práticas do dia a dia.

c) Exercitar a observação, descrição, comparação com diversos elementos e fenômenos "físicos" e "humanos" que interagem, constituindo paisagens.

A interação direta com os sujeitos locais que constituem o espaço e estabelecem diferentes relações com este e os demais sujeitos, gera a compreensão sistemática do funcionamento social, econômico e político, por exemplo. Essa compreensão mais complexa e completa favorece aos alunos um aprofundamento no entendimento dos conceitos geográficos e ambientais, demonstrando a importância da atuação do homem como agente fundamental na composição das diferentes paisagens, com as vantagens e desvantagens de sua ocupação nas diferentes formas de relevo e no meio ambiente.

Neste sentido, o trabalho de campo serviu como estimulo na medida em que agregou situações concretas, sugerindo uma aplicabilidade imediata. Foi capaz de propiciar a descrição, comparação, explicação e a compreensão dos diversos elementos que concorrem para a formação das paisagens geográficas. Para Castrogiovanni (1984), quando o aluno é capaz de vivenciar a geografia inserida no seu dia-a-dia, acaba concluindo que esta possui também uma utilidade prática na resolução de diversos problemas enfrentados e passa a valorizá-la como ciência.

\section{CONCLUSÕES}

A reflexão proporcionada pelos textos base, para a compreensão das temáticas abordadas neste trabalho, bem como a metodologia de ensino da geografia desenvolvida na aplicação da proposta de pesquisa, apresentaram contribuições importantes por ajudarem na construção de uma nova forma de se pensar a geografia, que faz parte de uma filosofia contemporânea e engloba o pensamento complexo, de onde podemos observar a necessidade da "religação dos 
saberes", teoria e prática, no processo de ensino aprendizagem. Além dessas contribuições, pode-se destacar a aprendizagem significativa de David Paul Ausubel que preconiza a aprendizagem eficiente como capaz de valorizar os conhecimentos prévios, reconfigurando ideias já existente na estrutura mental, se relacionando a novos conteúdos.

O trabalho de campo, com as visitas aos espaços previamente conhecidos na llha do Combú e Ilha de Caratateua, permitiu demonstrar para residentes e aos alunos da educação básica, a interdependência entre campo e cidade, repensar práticas educacionais para alunos que vivem no campo (dinâmica rural), mas estudam na cidade como no caso da escola Monsenhor de Azevedo, e conscientizar os alunos sobre a importância ecológica e econômica das várzeas na região das ilhas, constituindo-se a base da dieta alimentar do Nordeste do Estado do Pará.

A dinâmica constante de plantio e ocupação das áreas por atividades econômicas foi capas de despertar nos alunos discursões importantes sobre a responsabilidade ambiental. A percepção dos espaços interligados por sistemas sociais, econômicos e políticos, gera a necessidade de se pensar o estudo dos conceitos da geografia integrada e não mais isolada, como frequentemente ocorre nos espaços formais escolares. Por meio do plantio de mudas de açaí, por exemplo, os alunos puderam perceber a evolução da apropriação dos recursos, uma vez que o açaí vem sendo manejado de formas distintas ao longo do tempo, com técnicas que revelam um aprimoramento no processo de plantio, adubação e limpeza.

\section{REFERÊNCIAS BIBLIOGRÁFICAS}

AUSUBEL, D. P. A aprendizagem significativa: a teoria de David Ausubel. São Paulo: Moraes, 1982

AUSUBEL, D. P. Algunos aspectos psicológicos de la estrutuctura del conocimiento. Buenos Aires: El Ateneo, 1973.

ANDERSON, A.B. \& JARDIM, M.A.G. Cost and benefits of floodplain forest management by rural inhabitants in the Amazon Estuary: a case study of açaí palm production. In: J. O. Browder (ed.). Fragile lands of Latin AmericaStrategies for sustainable development. University of Tulane, Colorado, 1989; p.114-129.

CASTROGIOVANNI, A.C. Trabalho de campo no ensino da geografia na escola de 19 e 20 graus. Boletim Gaúcho de Geografia, 12: 71-74p,1984.

GAZETA. Chocolate rustico dona nena na ilha do Combu.

https://www.gazetadopovo.com.br/bomgourmet/chocolate-rustico-dona-nena-ilha-do-combu. Acesso em 17-122019 às 19:00

LIBÂNEO, J. C. Democratização da escola pública. São Paulo: Loyola, 1995.

JARDIM, M.A.G. \& VIEIRA, I. C.G. Composição florística e estrutura de uma floresta da Várzea do estuário amazônico, Ilha do Combu, Estado do Pará, Brasil. Boletim do Museu Paraense Emílio Goeldi, série Botânica 17: $2001 ; 333-354$

MORIN, Edgar. A cabeça bem-feita: repensar a reforma, reformar o pensamento. Tradução de Eloá Jacobina. 4 ed. Rio de Janeiro: Bertrand Brasil, 2003.128p.

MORIN; Edgar. ALMEIDA, Maria da Conceição de; CARVALHO, Edgar de Assis (Orgs.). Educação e complexidade: os sete saberes e outros ensaios. Tradução de Edgar de Assis Carvalho. São Paulo: Cortez, 2007.104p.

MOURA, O. S. DE, ILKIU-BORGES, A. L.; BRITO, E. da S. Brioflora (Bryophyta e Marchantiophyta) da llha do Combu, Belém, PA, Brasil. Hoehnea 40(1): 2013; p. 143-165.

QUEIROZ, J.A.L., MACHADO, S.A., HOSOKAWA, R.T. \& SILVA, I.C. Estrutura e Dinâmica de floresta de Várzea no estuário Amazônico no Estado do Amapá. Floresta 37: 2007; p. 339-352 
SANTOS, A. Complexidade e transdisciplinaridade em educação: cinco princípios para resgatar o elo perdido. Revista Brasileira de Educação v. 13 n. 37 2008. 72-186p.

SANTOS, M. Por uma outra globalização. Do pensamento único à consciência universal. São Paulo: Editora Record. 2000.

SOUZA, Sirius; CHIAPETTI, Rita. O TRABALHO DE CAMPO COMO ESTRATÉGIA NO ENSINO EM GEOGRAFIA Revista de Ensino de Geografia, Uberlândia, v. 3, n. 4, p. 3-22, jan./jun. 2012

SILVA, S.B. e. Belém e o Ambiente Insular. Universidade Federal Rural da Amazônia. 2010.165p.

PDIZZARI. A et al. Teoria da aprendizagem significativa segundo Ausubel. Revista PEC, Curitiba.v,2, n.1, p. 37-42. 2002 